\title{
Cellulose from the green macroalgae Ulva lactuca: isolation, characterization, optotracing, and production of cellulose nanofibrils
}

\author{
Niklas Wahlström • Ulrica Edlund (D) Henrik Pavia • Gunilla Toth • \\ Aleksander Jaworski • Andrew J. Pell • Ferdinand X. Choong • Hamid Shirani • \\ K. Peter R. Nilsson • Agneta Richter-Dahlfors
}

Received: 19 June 2019/ Accepted: 28 January 2020/Published online: 8 February 2020

(C) The Author(s) 2020

\begin{abstract}
We report (1) successful extraction and characterization of cellulose from northern hemisphere green macroalgae Ulva lactuca (Ulva fenestrata) collected along the Swedish west coast and cultivated indoors under controlled conditions, followed by (2) its utilization in the production of lignin-free cellulose nanofibrils (CNF). Cellulose was extracted by sequential treatment with ethanol, hydrogen peroxide, sodium hydroxide, and hydrochloric acid, yielding a celluloserich insoluble fraction. The extracted cellulose was disintegrated into CNF using a mechanical homogenization process without any further enzymatic pretreatments. In addition, regenerated cellulose was prepared. XRD characterization of the CNF showed characteristic peaks for the cellulose I allomorph and confirmed that the nanofibrils were semicrystalline with a crystallinity index of $48 \%$. Regenerated cellu-
\end{abstract}

Electronic supplementary material The online version of this article (https://doi.org/10.1007/s10570-020-03029-5) contains supplementary material, which is available to authorized users.

N. Wahlström · U. Edlund ( $\square)$

Fibre and Polymer Technology, KTH Royal Institute of

Technology, Teknikringen 56, 10044 Stockholm,

Sweden

e-mail: edlund@kth.se

H. Pavia - G. Toth

Department of Marine Sciences, Lovén Centre for Marine

Sciences - Tjärnö, University of Gothenburg,

45296 Strömstad, Sweden lose was mostly amorphous with an XRD pattern indicating the presence of the cellulose II allomorph. The cellulose fractions were essentially free from inorganic substances and thermally stable up to around $260{ }^{\circ} \mathrm{C}$. Structural mapping with CP-MAS ${ }^{13} \mathrm{C}-\mathrm{NMR}$ sustains the cellulose content of $\mathrm{CNF}$ and regenerated cellulose, respectively, yet ion chromatography identified the presence of $10-15 \%$ xylose in the fractions. Optotracing was used as a novel and non-disruptive tool to selectively assess the polysaccharide composition of the cellulose fractions and produced CNF aiming to shed light on this hitherto non-resolved origin of xylose in Ulva cell wall matter. Fluorescence excitation and emission spectra of a panel of 4 oligothiophenes identified and verified the presence of cellulose and sustain the conclusion that the isolated fractions consist of cellulose intertwined with a small amount of a xylose-containing glucan copolymer.
A. Jaworski · A. J. Pell
Department of Materials and Environmental Chemistry,
Arrhenius Laboratory, Stockholm University, Svante
Arrhenius väg 16C, 10691 Stockholm, Sweden
F. X. Choong · A. Richter-Dahlfors
Swedish Medical Nanoscience Center, Department of
Neuroscience, Karolinska Institutet, Stockholm, Sweden
H. Shirani · K. P. R. Nilsson
Department of Chemistry, IFM, Linköping University,
Linköping, Sweden 


\section{Graphic abstract}

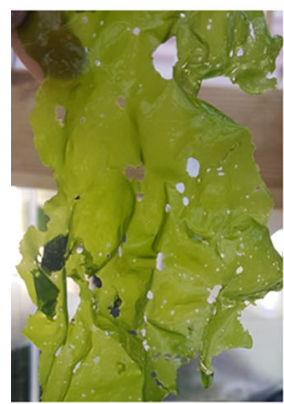

Ulva lactuca

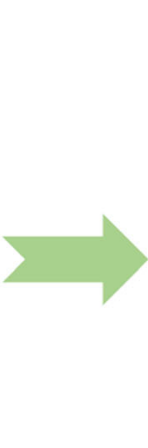

政

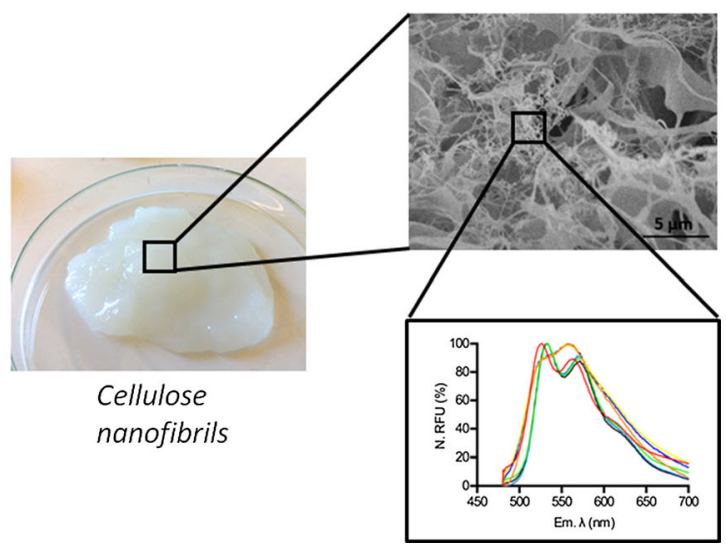

Keywords Nanocellulose $\cdot \mathrm{CNF} \cdot$ Extraction · Macroalgae - Ulva lactuca - Ulva fenestrata . Optotracing

\section{Introduction}

The use of cellulose-based materials has increased rapidly during the past decades (Przybysz and Buzala 2014). Due to its low weight, low cost, non-toxicity, high strength, and stiffness compared to many other commercially used polymer materials, biodegradability and recyclability, the market demand of cellulosebased materials is steadily increasing. The increasing use of cellulose-based materials is in line with the UN Sustainable Development Goals (Griggs et al. 2013) which endorses a transition from fossil-based materials to materials from renewable resources. Hitherto, the cellulose industry relies entirely on lignocellulosic feedstock from terrestrial plants, especially wood and cotton. The isolation of cellulose from wood requires removal of the lignin, which involves harsh chemical treatment of the biomass leading to partial degradation of the cellulose (Ververis et al. 2004). Delignification is energy consuming and the final cellulose fraction may contain residual chemicals from the ligninremoving process. In the native state, bio-synthesized cellulose chains tend to self-assemble into microfibrils which undergo further aggregation into larger assemblies, cellulose fibers, which build up terrestrial plant cell walls. Cellulose nanofibrils (CNF) are produced industrially by the disintegration of cellulose fibers into particles with diameters in nanoscale. Typically, CNF has a diameter of 5-50 $\mathrm{nm}$ and a length of a few micrometers. The CNF production usually involves an enzymatic or a chemical pre-treatment of cellulose pulp followed by a mechanical homogenization process. Cellulose fibers are exposed to high shear and pressure during the homogenization process, which will disintegrate cellulose fibers into the corresponding nanofibrils. Due to its excellent mechanical properties and environmental benefits, CNF can be used in a wide variety of applications such as composite materials, polymer films, foams, and in biomedical applications (Lavoine et al. 2012; Kargarzadeh et al. 2018; Bettaieb et al. 2015; Naderi 2017; Siró and Plackett 2010; Tayeb et al. 2018; Rocha et al. 2018; Shanmugam et al. 2017).

Aside from lignocellulosic biomass, cellulose is found in the cell walls of marine biomass such as macroalgae (Siddhanta et al. 2009, 2011, 2013; Koyama et al. 1997; Chen et al. 2016; Mihranyan 2011). Cellulose from macroalgae has gained increased attention recently since it offers several benefits compared with cellulose from land-based biomass. The absence of lignin in macroalgae leads to purer cellulose fractions, potentially more suitable for biomedical applications than lignocellulose (Halib et al. 2017). Also, the absence of lignin opens up for the possibility to extract the cellulose under milder conditions leading to less degraded cellulose fractions. Macroalgae is a low-cost source of biomass, which grows quickly, and cultivation does not require 
irrigation or arable land areas. Furthermore, macroalgae cultivation does not require the use of fertilizers and coastal eutrophication is avoided.

Cellulose has been successfully extracted from both red, green and brown macroalgae (Siddhanta et al. 2009, 2011, 2013; Koyama et al. 1997; Chen et al. 2016; Mihranyan 2011). The gross content of cellulose varies significantly between different species, ranging from 1 to $15 \% \quad(\mathrm{w} / \mathrm{w})$ (Siddhanta et al. 2009, 2011, 2013; Koyama et al. 1997). The cellulose content shows seasonal variations and is strongly dependent on the maturity of the biomass (Schiener et al. 2015; Starko et al. 2018). The green macroalgae genus Ulva is a group of cellulose-containing macroalgae. It is a commercially maricultured macroalgae, which belongs to a family of green alga called Chlorophyta. Ulva is widely distributed along the coastline in oceans across the world, which makes it an abundant, low-cost source of biomass. Ulva is particularly suitable for sea-based biomass production due to its high productivity and its good capability to thrive under different growing conditions worldwide. It has a high nutrition value with high levels of polysaccharides, proteins, vitamins and trace minerals (Taboada et al. 2010), making Ulva one of the most popular edible seaweeds worldwide. Cellulose is present in the cell walls of Ulva where it acts as a structural component together with the polysaccharide ulvan (Lahaye and Robic 2007). Interestingly, previous studies of the insoluble organic fraction extracted from Ulva, believed to consist of cellulose, report the presence of xylose residues aside glucose (Lahaye et al. 1994; Cronshaw et al. 1958; Dennis and Preston 1961). It was hypothesized that the cell wall matter consists of cellulose fibrils intertwined with either xylan or a xylose-glucose polymer, such as xyloglucan (Lahaye et al. 1994; Dennis and Preston 1961), or that the cellulose itself is not cellulose but rather a glucan decorated with xylose residues. Attempts to trace the origin of the xylose detected in carbohydrate analysis of extracted insoluble matter from Ulva was made with selective enzymatic hydrolysis, indicating that cellulose co-exist with a xylose-glucose polymer and that no xylan is present (Lahaye et al. 1994). However, it could not be concluded that cellulose I or cellulose II were present in the fraction.

A limitation of conventional carbohydrate compositional analyses, acid hydrolysis followed by gas chromatography (GC) or ion chromatography, is that the analyses report the gross monosaccharide composition but not the polysaccharide origin of the sugar residues. Hence, the origin of xylose in the insoluble fraction of Ulva cell walls will be very difficult to determine. A novel method for carbohydrate analysis, optotracing, opens new possibilities to determine the spatial and compositional structure of polysaccharides in plant tissues (Choong et al. 2016, 2018, 2019). Oligothiophenes bind selectively to glucans and produce unique spectral patterns that are recorded by excitation and emission fluorescence spectra and allow for new insights in the polysaccharide structure of biomass samples and plant tissues.

Previous studies on the isolation of cellulose from Ulva species, such as Ulva lactuca, involve treatment with methanol and hypochlorite bleaching of the biomass to remove pigments (Siddhanta et al. 2011). From a green chemistry point of view, methanol and hypochlorite are not preferred in a biorefinery process. Even though cellulose-rich fractions were extracted from Ulva lactuca in previous studies, there are still no studies on the production of CNF from the extracted cellulose. As mentioned previously, CNF has a high potential in material applications. The absence of lignin in Ulva lactuca makes it a potential feedstock for lignin-free CNF which may serve as a feasible alternative for $\mathrm{CNF}$ from lignocellulosic biomass in several material applications where a lignin-free CNF is preferred. Since the cultivation of Ulva lactuca can be sea-based it also offers benefits compared with land-based sources of lignin-free cellulose such as cotton. Cultivation of cotton typically requires large amounts of fresh water, and pesticides are often used. However, neither addition of fresh water nor pesticides is necessary for Ulva lactuca cultivation.

This work consists of two interlinked parts. We aim to (1) extract and characterize cellulose, and (2) produce lignin-free CNF from cellulose extracted from an Ulva species, green macroalgae, collected along the Swedish west coast. The aim is here to provide an additional source of CNF where-importantly-cellulose can be recovered and CNF produced without having to do delignification of the biomass at any point. Moreover, the cellulose resource is a lowcost biomass which do not required arable land or irrigation during cultivation. In addition, we apply optotracing as a novel method for carbohydrate analysis with the aim to shed new light on the carbohydrate composition of the extracted cellulose 
and the produced CNF. Even though Hughey et al. (2019) suggested that the oldest available name for the northern hemisphere 'Ulva lactuca' is Ulva fenestrata, we will refer to the species used in our study as Ulva lactuca for reasons of general understanding. In the cellulose extraction process, we will try to replace sodium hypochlorite and methanol with hydrogen peroxide and ethanol in an attempt to apply greener extraction conditions than those reported in previous studies. Furthermore, the CNF will be produced without any chemical or enzymatic defibrillating pre-treatment prior to the mechanical homogenization process. The extracted cellulose and the produced CNF will be thoroughly characterized with respect to crystallinity, microstructure, purity and chemical composition, and carbohydrate composition.

\section{Experimental}

\section{Materials}

Hydrogen peroxide $\left(\mathrm{H}_{2} \mathrm{O}_{2}, 30 \%\right.$, CAS nr: 7722-84-1), hydrochloric acid (37\%, CAS nr: 7647.01-0), sodium acetate (99\%, CAS nr: 127-09-3), sodium hydroxide ( $\mathrm{NaOH}, 99 \%$, CAS nr: 1310-73-2), lithium chloride (99\%, CAS-nr: 7447-41-8), dimethylacetamide (99\%, CAS-nr: 127-19-5), $\alpha$-cellulose, from Spruce wood (99\%, CAS-nr: 9004-34-6), L-(+)-arabinose (99\%, CAS nr: 5328-37-0), D-(+)-glucose (99\%, CAS nr: 50-99-7), D-(+)-mannose (99\%, CAS nr: 3458-28-4), D-(+)-galactose (99\%, CAS nr: 59-23-4), D-(+)xylose (99\%, CAS nr: 58-86-6), L-(+) rhamnose (99\%, CAS nr: 10030-85-0, D-(+)-glucoronic acid (98\%, CAS nr: 6556-12-3) and D-(+) galacturonic acid monohydrate (98\%, CAS-nr: 91510-62-2) were all purchased from Sigma Aldrich. Ethanol (99\%, CAS nr: 64-17-5) was purchased from VWR Chemicals. Iduronic acid (99\%, CAS nr: 2073-35-0,6119983-5) was purchased from CarboSynth.

\section{Cultivation of Ulva lactuca}

Ulva lactuca were collected from Inre Vattenholmen $\left(58^{\circ} 52^{\prime} 37.4^{\prime \prime} \mathrm{N} 11^{\circ} 6^{\prime} 52.1^{\prime \prime} \mathrm{E}\right)$ and brought back to the lab within $2 \mathrm{~h}$ of collection. Collected Ulva lactuca were rinsed several times in natural seawater to remove grazers and loose epiphytes. The seaweeds were placed into cultivation tanks $(90 \mathrm{~L})$ under a neutral light cycle (16 h daylight, $8 \mathrm{~h}$ darkness) at a light intensity of $140 \mu \mathrm{E} \mathrm{m}^{-2} \mathrm{~s}^{-1}$. The light source was an INDY66 LED $60 \mathrm{~W} 4000 \mathrm{~K} 6000 \mathrm{~lm}$. The seaweeds continuously received filtered seawater that was passed through $1 \mu \mathrm{m}$ filters. No additional medium or chemicals were added to the water. The natural seawater used in the flow-through system was pumped in from the bay outside the Tjärnö Marine Laboratory ( $\left.58^{\circ} 52^{\prime} 36.4^{\prime \prime} \mathrm{N} 11^{\circ} 6^{\prime} 42.84^{\prime \prime} \mathrm{E}\right)$. Thus, the salinity and temperature fluctuated depending on the prevailing weather and seasonal conditions. During the cultivation period (March-May 2018), the salinity ranged from 11 to $25 \mathrm{PSU}$ and the temperature increased from 4 to $19{ }^{\circ} \mathrm{C}$.

\section{Extraction of cellulose}

The extraction of the cellulose was performed using the method suggested by Siddhanta et al. (2009) with some modifications to avoid the use of sodium hypochlorite and methanol. The extraction procedure is schematically shown in Fig. 1. Freeze-dried Ulva lactuca $(50 \mathrm{~g})$ was ground to a fine powder using a Bosch MKM6003 coffee miller (Clas Ohlson, Sweden) and subjected to Soxhlet extraction in EtOH $(85 \%)$ for $24 \mathrm{~h}$ at $120{ }^{\circ} \mathrm{C}$ to remove pigments and fatty acids. The liquid phase was discarded and the insoluble fraction was washed several times with EtOH (99\%) and dried in an oven at $37{ }^{\circ} \mathrm{C}$ for $16 \mathrm{~h}$. After drying, the sample was further treated to remove residual green pigments and other colored impurities by suspending the sample in $400 \mathrm{~mL}$ of $4 \% \mathrm{H}_{2} \mathrm{O}_{2}$ followed by heating of the mixture to $80{ }^{\circ} \mathrm{C}$ for $16 \mathrm{~h}$. After cooling to room temperature, the mixture was centrifuged at $5000 \mathrm{rpm}$ for $15 \mathrm{~min}$ and the supernatant was discarded. The insoluble fraction was washed several times with water until the $\mathrm{pH}$ of the washing water was 7 and was then suspended in $400 \mathrm{~mL}$ of $0.5 \mathrm{M} \mathrm{NaOH}$. The mixture was kept at $60{ }^{\circ} \mathrm{C}$ for $16 \mathrm{~h}$. After cooling to room temperature, the mixture was centrifuged at $5000 \mathrm{rpm}$ for $15 \mathrm{~min}$ and the supernatant was discarded. The insoluble fraction was washed several times with water until the $\mathrm{pH}$ of the washing water was 7 and the insoluble fraction was then suspended in $200 \mathrm{~mL}$ of $5 \%$ (v/v) $\mathrm{HCl}$. The mixture was heated to boiling and then cooled to $30{ }^{\circ} \mathrm{C}$ and kept at this temperature for $16 \mathrm{~h}$. The solution was centrifuged at $5000 \mathrm{rpm}$ for $15 \mathrm{~min}$ and the supernatant was discarded. The insoluble fraction 


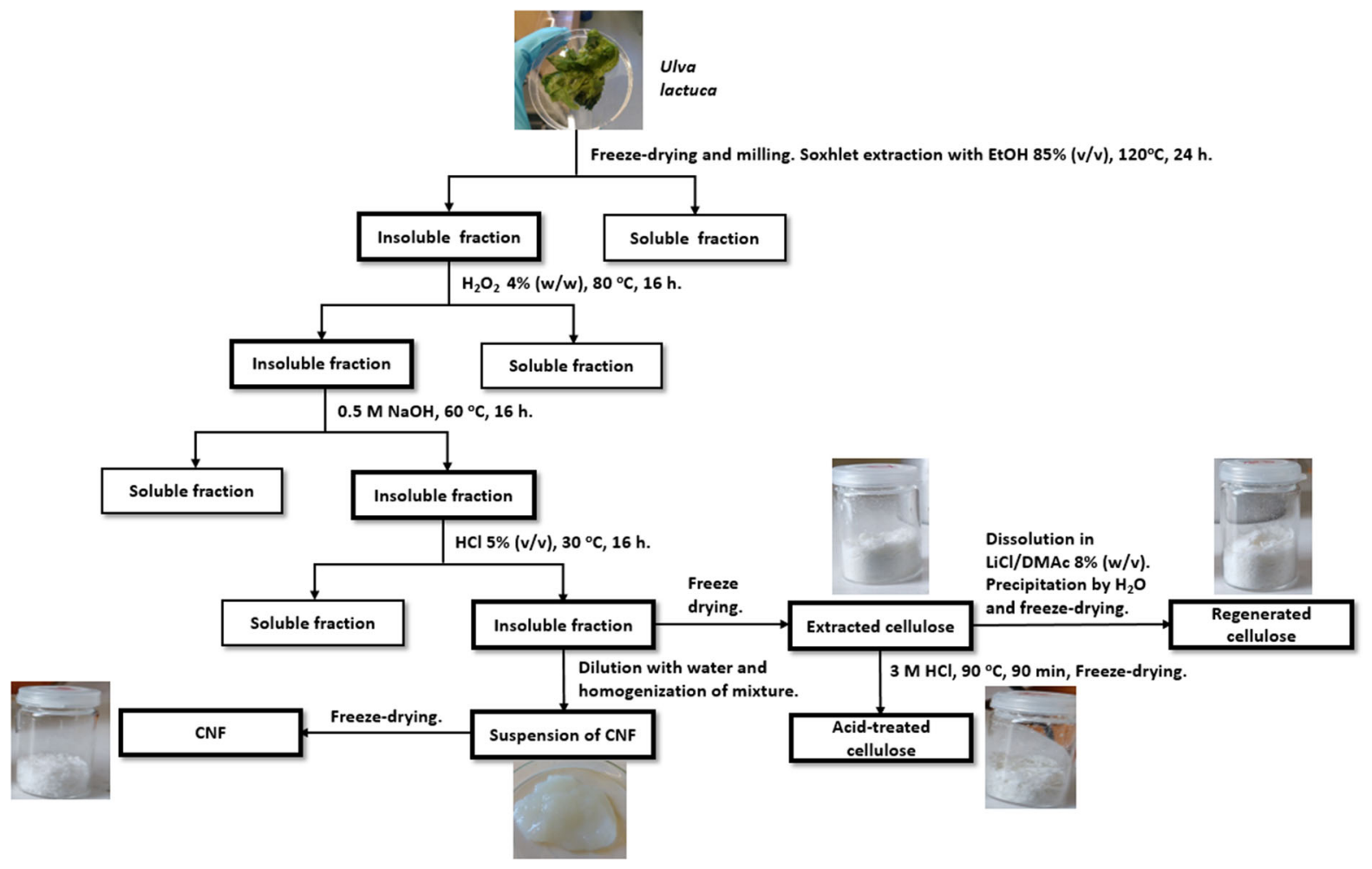

Fig. 1 Extraction protocol for the isolation of cellulose and production of CNF from Ulva lactuca

containing cellulose was washed several times with water until the $\mathrm{pH}$ of the washing water was 7 , collected and freeze-dried.

\section{Dissolution and regeneration of extracted cellulose}

Freeze-dried extracted cellulose $(0.5 \mathrm{~g})$ was dissolved in $100 \mathrm{~mL}$ dimethylacetamide (DMAc) containing $8 \%$ $(\mathrm{w} / \mathrm{v}) \mathrm{LiCl}$ and stirred at $80{ }^{\circ} \mathrm{C}$ for $16 \mathrm{~h}$ until the complete dissolution of the cellulose. The solution was cooled to room temperature and the dissolved cellulose was regenerated by the dropwise addition of $\mathrm{LiCl} /$ DMAc solution to $100 \mathrm{~mL}$ of water. The mixture was centrifuged at $5000 \mathrm{rpm}$ for $15 \mathrm{~min}$ and the supernatant was discarded. The insoluble fraction containing the regenerated cellulose was washed with water, collected and freeze-dried.

Homogenization of the extracted cellulose for the preparation of $\mathrm{CNF}$

Cellulose was extracted as described above, but instead of freeze drying, the extracted cellulose was kept as a suspension in water and diluted to $250 \mathrm{~mL}$ with distilled water. The resulting slurry was mechanically disintegrated in a homogenizer (M-110EH, Microfluidics Corp, United States). The slurry was first passed through two large chambers in series (400 and $200 \mu \mathrm{m}$, respectively) at 925 bar. Thereafter, the samples were passed through two smaller chambers in series (200 and $100 \mu \mathrm{m}$, respectively) at 1600 bar four times in total. The remaining slurry after the process was freeze-dried for further characterization.

\section{Acid treatment of extracted cellulose}

To obtain a cellulose fraction with higher crystallinity, a subsample $(0.5 \mathrm{~g})$ of the extracted cellulose was treated with $100 \mathrm{~mL} 3 \mathrm{M} \mathrm{HCl}$ at $90{ }^{\circ} \mathrm{C}$ for $90 \mathrm{~min}$. After cooling to room temperature, the mixture was centrifuged at $5000 \mathrm{rpm}$ for $15 \mathrm{~min}$ and the supernatant was discarded. The insoluble fraction was washed several times with water until the $\mathrm{pH}$ of the washing water was 7 and the insoluble fraction was collected and freeze-dried. 
Characterization

\section{Attenuated total reflectance Fourier transform infrared spectroscopy (ATR-FTIR)}

FTIR spectra of the dried cellulose fractions were recorded between 4000 and $600 \mathrm{~cm}^{-1}$ at room temperature using a Perkin-Elmer Spectrum 100 FTIR with a triglycine detector and equipped with an attenuated total reflectance crystal accessory (ATR Golden Gate) from Graseby Specac LTD (Kent, England). Corrections were made for atmospheric water and carbon dioxide. The obtained spectra were calculated as an average of 64 scans. The data were analyzed using PerkinElmer Spectrum software.

\section{High-performance anion exchange chromatography with pulsed amperometric detection (HPAEC-PAD)}

The monosaccharide and uronic acid composition of the cellulose fractions were measured with an HPAEC-PAD. Acid hydrolysis of the cellulose fractions to hydrolyze the cellulose into monosaccharides was performed by adding $0.8 \mathrm{~mL} 72 \% \mathrm{H}_{2} \mathrm{SO}_{4}$ to approximately $10 \mathrm{mg}$ sample. The samples were left on a shaking board at room temperature for $90 \mathrm{~min}$. Thereafter, $9.2 \mathrm{~mL}$ of water was added to obtain a final volume of $10 \mathrm{~mL}$. The samples were placed on a shaking board and left for $70.5 \mathrm{~h}$ at $80{ }^{\circ} \mathrm{C}$. The composition of monosaccharides was determined using a HPAEC-PAD (HPAEC-PAD, ICS-3000 Dionex, Sunnyvale, CA, USA). The column was a CarboPac PA1 $(4 \times 250 \mathrm{~mm})$ column, and MilliQ water, $0.26 \mathrm{M} \mathrm{NaOH}$ and $0.17 \mathrm{M} \mathrm{NaAc}$ were used as the mobile phase. A mixture of fucose, arabinose, rhamnose, galactose, glucose, xylose, mannose, galactoronic acid, glucuronic acid, and iduronic acid was used as the reference sample. The data were processed and analyzed using Chromelon 7.1.

Thermal gravimetric analysis (TGA)

The thermal stability of the cellulose fractions, char and ash contents of Ulva lactuca before extraction and the cellulose fractions, were estimated using a Mettler Toledo TGA/DSC. Approximately $4 \mathrm{mg}$ of each freeze-dried sample was heated in alumina cups from 40 to $800{ }^{\circ} \mathrm{C}$ at a heating rate of $10{ }^{\circ} \mathrm{C} / \mathrm{min}$ under an $\mathrm{N}_{2}$ atmosphere. After being heated to $800{ }^{\circ} \mathrm{C}, \mathrm{O}_{2}$ was introduced instead of $\mathrm{N}_{2}$ and the temperature was kept at $800{ }^{\circ} \mathrm{C}$ for $15 \mathrm{~min}$. The flow rate was set to $50 \mathrm{~mL} /$ min. The char content was calculated as the weight that remained after the samples were heated to $800{ }^{\circ} \mathrm{C}$ in $\mathrm{N}_{2}$ and the ash content was calculated as the mass remaining after finalizing the heating program. The data were processed and analyzed using STARe software.

Field-emission scanning electron microscopy (FESEM)

The morphology of the CNF was observed by ultrahigh-resolution field emission scanning electron microscopy (FE-SEM) using a Hitachi S-4800 operating at $5 \mathrm{kV}$. The CNF was freeze-dried overnight and then attached to the sample supports using doublesided adhesive carbon tape and sputter-coated with a $7 \mathrm{~nm} \mathrm{Pt} / \mathrm{Pd}$ layer using a Cressington 208HR under an inert atmosphere.

\section{X-ray diffraction (XRD)}

The crystal structure and the crystallinity index of the cellulose samples were measured at room temperature using an Empyrean PAN-analytical XRD operating at $45 \mathrm{kV}$ and $45 \mathrm{~mA}$ using monochromatic $\mathrm{CuK} \alpha$ radiation $(\lambda=0.1541 \mathrm{~nm})$ in the range $2 \theta=10^{\circ}-40^{\circ}$ with a scan rate of $1.0 \mathrm{~min}^{-1}$. The crystallinity index $\mathrm{Crl}(\%)$ was calculated using Eq. 1 (Segal et al. 1959):

$\operatorname{Crl}(\%)=\frac{I_{200}-I_{a m}}{I_{200}} \times 100$

where $I_{200}$ is the intensity of the crystalline peak at $2 \theta=22^{\circ}$ corresponding to the (200) plane and $\mathrm{I}_{\mathrm{am}}$ is the intensity at the local minimum of the curve at $2 \theta=18^{\circ}$ corresponding to the amorphous regions of the cellulose.

\section{Atomic force microscopy (AFM)}

The morphology of the CNF in the dry state was analyzed using AFM (Multimode V, Bruker, Santa Barbara, CA). Silicon wafers $(1 \times 1 \mathrm{~cm})$ were used as substrates for the adsorption. The wafers were washed with absolute EtOH and MilliQ water. After washing, the wafers were placed in an air plasma cleaner (model PCD 002, Harrick Scientific Corporation, NY) for $3 \mathrm{~min}$ at $30 \mathrm{~W}$. The wafers were immersed in $0.1 \mathrm{M}$ 
$\mathrm{NaOH}$ for 2 min after which it was immersed in a $0.020 \mathrm{~g} / \mathrm{L}$ solution of polyethyleneimine (PEI) for $2 \mathrm{~min}$. After washing with water, the samples were immersed in a $0.06 \mathrm{mg} / \mathrm{mL}$ suspension of CNF in water for $2 \mathrm{~min}$. The samples were dried using a flow of nitrogen gas.

The silicon wafers were attached to AFM specimen disc. The images were taken in the scanning-mode in height, amplitude and phase modes by using an RTSP silica cantilever (Bruker) having a spring constant of $5 \mathrm{Nm}$, a tip radius of $8 \mathrm{~nm}$ and a resonance frequency of 150-200 kHz. Nanoscope Software (version 1.4, Bruker Corporation) was used for data processing.

Solid-state nuclear magnetic resonance spectroscopy (NMR)

${ }^{1} \mathrm{H} \rightarrow{ }^{13} \mathrm{C}$ cross-polarization magic-angle-spinning (CPMAS) NMR spectra were collected on a Bruker Avance-III NMR spectrometer at a magnetic field strength of 14.1 T (Larmor frequencies of 600.1 and $150.9 \mathrm{MHz}$ for ${ }^{1} \mathrm{H}$ and ${ }^{13} \mathrm{C}$, respectively) using $4.0 \mathrm{~mm}$ zirconia rotors at a MAS rate of $14.00 \mathrm{kHz}$. Acquisitions involved proton 90 degree excitation pulse of $4 \mu$ s and matched spin-lock fields that obeyed a modified Hartmann-Hahn condition $v_{\mathrm{H}}=v_{\mathrm{C}}+v_{\mathrm{r}}$. Contact time of 500 us was used and SPINAL-64 proton decoupling at $60 \mathrm{kHz}$. From 16,384 to 24,576 signal transients with $4 \mathrm{~s}$ relaxation delays were collected for each sample. Chemical shifts were referenced with respect to neat tetramethylsilane (TMS).

\section{Synthesis of optotracers}

q-FTAA, p-FTAA and h-FTAA was synthesized as reported previously ( Aslund et al. 2009; Klingstedt et al. 2011) and HS-310 was synthesized as outlined below. Chemicals and solvents were obtained from commercial sources and used as received (Scheme 1).

Microwave reaction was performed using Biotage Initiator microwave system. TLC was carried out on Merck precoated 60 F254 plates using UV-light $(\lambda=254 \mathrm{~nm}$ and $366 \mathrm{~nm})$ and charring with ethanol/sulfuric acid/p-anisaldehyde/acetic acid 90:3:2:1 for visualization. NMR spectra were recorded on a Varian 300 instrument (Varian Inc., Santa Clara, CA, USA) operating at $300 \mathrm{MHz}$ for $1 \mathrm{H}$ and $75.4 \mathrm{MHz}$ for $13 \mathrm{C}$, using the residual solvent signal as reference. Analytical liquid chromatography/mass spectrometry (LC/MS) was performed on a Waters system equipped with a Waters 1525 gradient pump, 2998 Photodiode Array Detector, 2424 Evaporative Light Scattering Detector, SQD 2 Mass Detector and an Xbridge ${ }^{\circledR} \mathrm{C} 18$ column $(4.6 \times 50 \mathrm{~mm}, 3.5 \mu \mathrm{m})$.

A mixture of dimer 1 (115 mg, $0.272 \mathrm{mmol}), 5,5^{\prime}-$ dibromo-2-2'-bithiophene (2) (40 mg, $0.123 \mathrm{mmol}$ ), $\mathrm{K}_{2} \mathrm{CO}_{3} \quad$ (86 mg, $\left.0.618 \mathrm{mmol}\right)$ and PEPPS-IPr (4 mol\%) in 1,4-dioxane/methanol (8: $2,3 \mathrm{~mL} / \mathrm{mmol}$, degassed) were added to a reaction vial, back filled with nitrogen and the mixture was heated at $100{ }^{\circ} \mathrm{C}$ in microwave system for $30 \mathrm{~min}$. After cooling to room temperature, the reaction was quenched by glacial acetic acid and water $(20 \mathrm{~mL})$ added. The residue was extracted with DCM $(3 \times 40 \mathrm{~mL} / \mathrm{mmol})$, washed with water $(2 \times 30 \mathrm{~mL})$, brine $(30 \mathrm{~mL})$ and the combined organic phase was dried over $\mathrm{Na}_{2} \mathrm{SO}_{4}$, filtrated and the solvent was evaporated. The crude product was treated with warm $\mathrm{MeOH}$ and filtrated to obtain hexamer as red solid, yield: $0.35 \mathrm{~g} \mathrm{(38 \% ).}$

The hexamer was dissolved in 1,4-dioxane/water (9:1) and hydrolyzed with $\mathrm{NaOH}$ (1 M, aqueous, 1.5 equiv./ester) at $80{ }^{\circ} \mathrm{C}$ for $16 \mathrm{~h}$. The solution was lyophilized to render HS-310 as a red solid with quantitative yield.

${ }^{1} \mathrm{H}$ NMR $\left(300 \mathrm{MHz}, \mathrm{D}_{2} \mathrm{O}\right) \delta 7.31(\mathrm{~d}, \mathrm{~J}=3.9 \mathrm{~Hz}$, $1 \mathrm{H}), 6.95(\mathrm{~s}, 2 \mathrm{H}), 6.89(\mathrm{~d}, \mathrm{~J}=3.9 \mathrm{~Hz}, 1 \mathrm{H}), 6.86(\mathrm{~s}$, 1H), 3.50 (s, 2H). 13C NMR (126 MHz, D2O) $\delta$ 179.0, 169.5, 139.9, 139.7, 135.6, 135.1, 134.9, 134.7, 131.3, 130.9, 128.0, 125.7, 124.8, 124.6, 38.3. LCMS (ESI): $\mathrm{m} / \mathrm{z}$ calcd for $\mathrm{C}_{30} \mathrm{H}_{18} \mathrm{O}_{8} \mathrm{~S}_{6}(\mathrm{M}+\mathrm{H}) 698.9$ found: 699.7 .

Optotracers and carbohydrates

Stock solutions $(1 \mathrm{mg} / \mathrm{mL})$ of h-FTAA, HS-310, p-FTAA and q-FTAA in deionized water were stored at $4{ }^{\circ} \mathrm{C}$. Microcrystalline cellulose fibres (M. cellulose, $100 \mu \mathrm{m}$ ) from cotton liners (CAS no. 9004-34-6) were from Sigma-Aldrich, Stockholm, Sweden, and used as reference samples to compare with the aglae fraction produced in this work. Xyloglucan and xylose were obtained from Sigma-Aldrich. Polysaccharides were maintained as $2 \mathrm{mg} / \mathrm{mL}$ stock solutions at $4{ }^{\circ} \mathrm{C}$. 


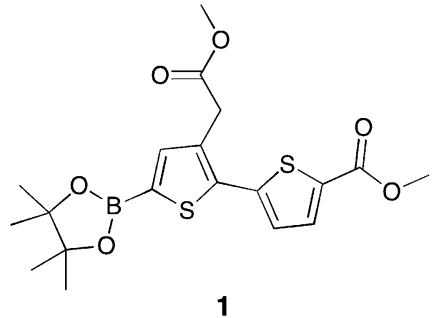

1

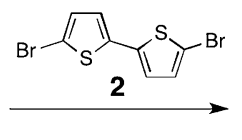

(i, ii)

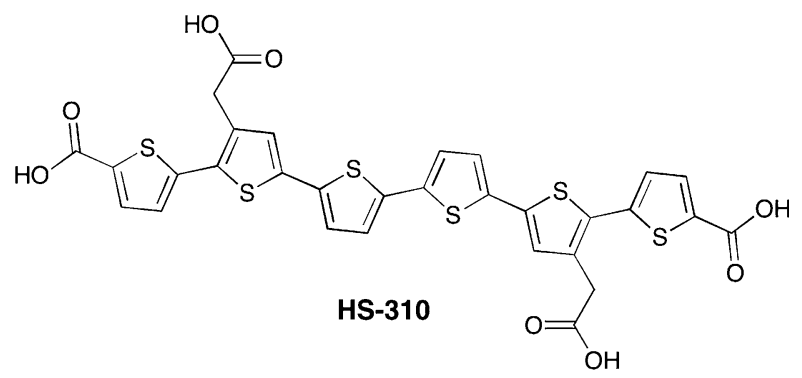

Scheme 1 Reagents and conditions: (i) 1,4-dioxane/MeOH, PEPPSI ${ }^{\mathrm{TM}}$-IPr, $\mathrm{K}_{2} \mathrm{CO}_{3}$, microwave $100{ }^{\circ} \mathrm{C}, 30 \mathrm{~min}$; (ii) $\mathrm{NaOH}$ (1 M), 1,4-dioxane $/ \mathrm{H}_{2} \mathrm{O}, 80^{\circ} \mathrm{C}, 16 \mathrm{~h}$

Optical recordings of optotracer-carbohydrate interactions

Aliquots $(100 \mu \mathrm{L})$ of each carbohydrate stock solution were pipetted into individual wells of a white 96-well round bottom microtiter plate (Corning, Stockholm, Sweden). Optotracer stock solutions were diluted in PBS, pH 7.4, (Sigma-Aldrich, Stockholm, Sweden) to a final concentration of $1.33 \mu \mathrm{g} / \mathrm{mL}$, from which $100 \mu \mathrm{L}$ was added to each well. Samples were sealed with adhesive PCR plate seals (Termo-Fischer, Stockholm, Sweden) and incubated at $4{ }^{\circ} \mathrm{C}$ on a rocking shaker for $30 \mathrm{~min}$. The plate was then positioned in a Synergy MX platereader (Biotek, Stockholm, Sweden), the excitation spectra (emission at $545 \mathrm{~nm}$ ) were collected between 300 and $525 \mathrm{~nm}$ and the emission spectrum (excitation at $450 \mathrm{~nm}$ ) was collected between 475 and $700 \mathrm{~nm}$. Spectra were collected with the instruments' 'top-down' setting with $1 \mathrm{~nm}$ steps. Data from experiments performed in triplicates were processed and analyzed using Prism 6 (Graphpad, USA).

\section{Results and discussion}

This work consists of two interlinked parts: (1) cellulose extracted from the green macroalgae Ulva lactuca collected along the Swedish west coast, and (2) the subsequent production and characterization of cellulose nanofibrils (CNF) from extracted cellulose. In the first part, the cellulose was extracted using a four-step process involving sequential treatment of the biomass by $\mathrm{EtOH}, \mathrm{H}_{2} \mathrm{O}_{2}, \mathrm{NaOH}$, and $\mathrm{HCl}$, after which the cellulose was left as an insoluble fraction. In the second part, CNF was produced from the extracted cellulose with no further pre-treatments using a mechanical homogenization process to generate lignin-free CNF. The chemical composition, crystallinity, and morphology of the produced CNF were investigated. Both extracted cellulose and the produced CNF contain xylose residues, the origin of which cannot be understood with ion chromatography. Investigation by optotracing confirmed that the extracted cellulose fraction indeed contain high-purity cellulose, mixed with a xylose-glucose polysaccharide.

\section{Extraction of cellulose}

About $1.1 \mathrm{~g}$ of extracted cellulose was obtained in the extraction starting from $50.0 \mathrm{~g}$ freeze-dried biomass, giving an overall yield of $2.2 \%(\mathrm{w} / \mathrm{w})$ on a dry weight basis. This value is very similar to the value reported from extraction of Ulva lactuca collected in France (Lahaye et al. 1994) but lower than the yield reported from the extraction of cellulose from Ulva lactuca collected in India (Siddhanta et al. 2009). The chemical composition of Ulva lactuca is strongly dependent on the local growing conditions, so Ulva lactuca collected along the west coast of Sweden cannot be directly compared to Ulva lactuca from other localities. The age of algae individuals is another factor that strongly influences the chemical composition (Starko et al. 2018). Ulva lactuca individuals used in this study were harvested at an early stage of maturity, which likely caused an overall lower content of cellulose.

After the dissolution of $0.5 \mathrm{~g}$ of the extracted cellulose fraction in $\mathrm{LiCl} / \mathrm{DMAc}$ followed by precipitation and freeze-drying, $0.35 \mathrm{~g}$ of regenerated cellulose was obtained which corresponds to $70 \%$ (w/w) of 
the dissolved cellulose. This means that $30 \%(\mathrm{w} / \mathrm{w})$ of the dissolved cellulose remains in the supernatant after precipitation. A possible explanation is that dissolution and heating of cellulose in $\mathrm{LiCl} / \mathrm{DMAc}$ lead to partial degradation of the cellulose over time due to random cleavage of the glycosidic bonds (Potthast et al. 2002, 2003) The cleavage of the glycosidic bonds leads to a decrease in the average molecular weight and formation of low molecular weight fragments. These fragments might be soluble in the DMAc/water mixture and will not precipitate upon addition of water. Another possibility is that the extracted cellulose fraction contains smaller amounts of other Ulva lactuca cell-wall polysaccharides such as xyloglucan or ulvan which may have a higher solubility than cellulose in the DMAc/water mixture and thus not fully precipitate upon the addition of water.

After the acidic treatment of $0.5 \mathrm{~g}$ of the extracted cellulose, $0.34 \mathrm{~g}$ cellulose remained as an insoluble fraction, which means that the cellulose was partially degraded during the acidic treatment. The degradation process is caused by acid hydrolysis which causes cleavage of the glycosidic bonds.

Extracted cellulose was mechanically disintegrated in a homogenizer to produce $\mathrm{CNF}$, as further discussed below.

Structural characterization of the extracted cellulose and $\mathrm{CNF}$

HPAEC-PAD analysis on the cellulose fractions was carried out to determine the carbohydrate composition, targeting, in particular, the glucose purity indicating if the cellulose fractions contain other cell-wall carbohydrates such as ulvan, xylan and xyloglucan. The chromatograms with assigned peaks from the HPAEC-PAD analysis are shown in the supporting information (Figs. S1-S4).

The cellulose fractions extracted from Ulva lactuca contain mostly glucose (Table 1), but also a smaller amount of xylose, which sustains that indeed a glucose-rich polysaccharide was isolated in the extraction. This is in agreement with previous studies, which showed that an insoluble fraction consisting of mostly glucose and smaller amounts of xylose is obtained if Ulva lactuca is bleached and treated with alkali (Lahaye et al. 1994; Bobin-Dubigeon et al. 1997; Cronshaw et al. 1958; Ray and Lahaye 1995). However, the origin of the xylose moieties is still not fully established. Lahaye et al. (1994) used enzymatic depolymerization of the extracted cellulose followed by HPLC analysis in an attempt to identify the origin of the xylose. Their analysis suggests that the extracted cellulose is likely a mixture of cellulose and smaller amounts of xyloglucan rather than the cellulose chain itself carrying the xylose residues. As shown in our study, neither pigment removal nor an additional post-production acidic treatment removed the xylose from the sample. Even after treatment with $3 \mathrm{M} \mathrm{HCl}$, the sample still contains xylose. This is a possible indication that xylose and glucose units are, at least to some extent, covalently linked and that the cellulose is indeed a mixture of pure cellulose and a xylose-glucose polymer such as xyloglucan. Another possibility is that the insoluble fraction consists only of a glucose-xylose polysaccharide and not true cellulose I or II at all. Rhamnose, glucuronic acid, and iduronic acid were not found in the samples verifying that there is no ulvan in the samples. The overall carbohydrate content in the regenerated cellulose fraction was lower than in the extracted cellulose and the CNF. This can be explained by the fact that cellulose partially degrades upon dissolution in $\mathrm{LiCl} /$ DMAc at higher temperatures. One of the suggested degradation mechanisms is the peeling and degradation of monomer units at the reducing end of the cellulose chain (Potthast et al. 2002, 2003). The degradation of the monomers will lead to a lower monosaccharide content in the regenerated sample and therefore a lower carbohydrate content. The acidtreated cellulose had the highest carbohydrate content with an overall carbohydrate content of $89 \%$ (w/w), probably because the acid-treatment removed impurities that were present in the extracted cellulose. Another interesting observation is that the regenerated cellulose had a lower relative amount of xylose (10\%) compared with the extracted cellulose and CNF $(15 \%)$. This is another indication that the extracted cellulose fraction is a mixture of cellulose and xyloglucan. The xyloglucan is likely to have a higher solubility in the DMAc/water mixture and will not precipitate completely. Consequently, the regenerated cellulose will be more enriched in pure cellulose than the extracted cellulose before dissolution. The acidtreated cellulose also contains a lower relative amount of xylose $(9 \%)$ than the extracted cellulose and CNF $(15 \%)$ further sustaining that the xyloglucan was partly removed during the acid-treatment process. In 
Table 1 The carbohydrate and uronic acid composition of cellulose fractions extracted from Ulva lactuca given as the amount (mg carbohydrate/g sample)

\begin{tabular}{llllllllr}
\hline Sample & Rha & Ara & Gal & Glc & Xyl & Man & GlcA & IduA \\
\hline Extracted cellulose & - & - & - & $731(85)$ & $124(15)$ & - & - & - \\
Regenerated cellulose & - & - & - & $705(90)$ & $81(10)$ & - & - & - \\
CNF & - & - & - & $731(85)$ & $124(15)$ & - & - & - \\
Acid-treated cellulose & - & - & - & $814(91)$ & $79(9)$ & - & - & - \\
\hline
\end{tabular}

The abbreviations for the carbohydrates are as follows: Rha rhamnose, Ara arabinose, Gal galactose, Glc glucose, Xyl xylose, Man mannose, GlcA glucuronic acid, and $I d u A$ iduronic acid. The total carbohydrate content was calculated as the sum of all monosaccharides and uronic acids in each sample. Numbers within parenthesis represent the carbohydrate composition given as the relative $\%$ of organic material calculated from the mass of each sugar divided by the total mass of carbohydrates

-Below detection limit

conclusion, the HPAEC-PAD analysis verifies the absence of ulvan and indicates that the extracted fractions contain cellulose mixed with a xyloseglucose polysaccharide, but cannot convincingly verify that the fractions contain cellulose I or II. Further characterization is necessary.

The cellulose fractions were further analyzed by FTIR (Fig. 2). Lists of all assigned peaks are included in the Supporting information (Tables S1-S4). The FTIR spectra of the cellulose fractions show many of the characteristic peaks for polysaccharides. The broad bands at $3500-3200 \mathrm{~cm}^{-1}$ correspond to the $\mathrm{O}-\mathrm{H}$ stretching for the hydroxyl groups and the bands in the range $3000-2800 \mathrm{~cm}^{-1}$ correspond to $\mathrm{C}-\mathrm{H}$ stretching. The peaks at $1420 \mathrm{~cm}^{-1}$ and $1315 \mathrm{~cm}^{-1}$

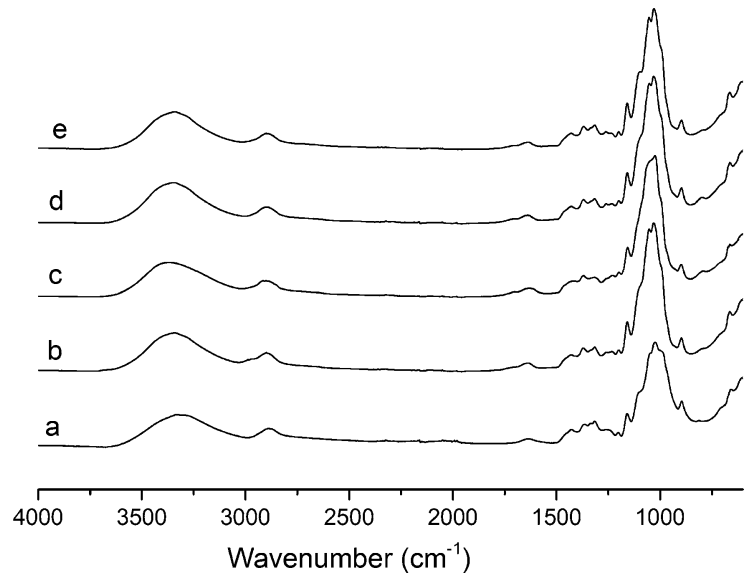

Fig. 2 FTIR spectra of cellulose fractions extracted from Ulva lactuca: (a) cellulose reference from Spruce wood, (b) extracted cellulose from Ulva lactuca, (c) regenerated cellulose from Ulva lactuca, (d) CNF from Ulva lactuca and (e) acid treated cellulose from Ulva lactuca correspond to $\mathrm{H}-\mathrm{C}-\mathrm{H}$ scissor vibration and $\mathrm{H}-\mathrm{C}-\mathrm{H}$ tip vibration, respectively. The sharp peaks around $1020-1050 \mathrm{~cm}^{-1}$ correspond to symmetric stretching of $\mathrm{C}-\mathrm{O}-\mathrm{C}$ linkages. The small peak around $895 \mathrm{~cm}^{-1}$ is characteristic of the $\beta$-glycosidic bond, which is a strong indication of the presence of polymeric polysaccharides such as cellulose (Ververis et al. 2004). Importantly, the spectra show no traces of strong peaks around $1220 \mathrm{~cm}^{-1}$ and $840-845 \mathrm{~cm}^{-1}$. These peaks correspond to $\mathrm{S}=\mathrm{O}$ stretching and $\mathrm{C}-\mathrm{O}-\mathrm{S}$ stretching and are characteristic of the polysaccharide ulvan, a major component of Ulva lactuca. The absence of such peaks hence indicates that ulvan was successfully removed from the cellulose fraction using the proposed fractionation protocol, which is in agreement with the results from the HPAEC-PAD analysis. Furthermore, no peak around $1550 \mathrm{~cm}^{-1}$ corresponding to $\mathrm{N}-\mathrm{H}$ bending in proteins was observed indicating that the cellulose samples were free from proteins. A small peak is observed around $1710 \mathrm{~cm}^{-1}$, possibly corresponding to $\mathrm{C}=\mathrm{O}$ stretching in oxycellulose (Zeronian and Inglesby 1995) indicating that oxidation of cellulose into oxycellulose took place to a minor extent during the extraction, probably during the bleaching step with hydrogen peroxide. Oxidation of xyloglucan probably also occurred to some extent. No significant differences were observed between the extracted, regenerated, and the CNF samples and all the samples show all the peaks that are expected for cellulose. 
Thermal characterization of the extracted cellulose and $\mathrm{CNF}$

Ulva lactuca before fractionation, the extracted cellulose fractions, and the produced CNF were further analyzed by TGA. The ash and char contents are given in Table 2 and the TG and DTG curves are shown in Figs. 3 and 4. The mass of the cellulose fractions decreases by $4 \%(\mathrm{w} / \mathrm{w})$ at temperatures up to $100{ }^{\circ} \mathrm{C}$. This is caused by the evaporation of bound water. The largest decrease in mass starts at around $260{ }^{\circ} \mathrm{C}$, which is caused by the thermal degradation of cellulose. This indicates that the cellulose in Ulva lactuca is thermally stable up to this temperature. Previous studies have shown that the thermal stability of cellulose from seaweed varies between species (Lakshmi et al. 2017; Chen et al. 2016; Singh et al. 2017) and is usually in the range $250-300{ }^{\circ} \mathrm{C}$. The thermal stability increases with increasing crystallinity index of the cellulose. By comparing the TGA curves for the extracted cellulose and the regenerated cellulose, respectively, it is clear that the regenerated cellulose starts to decompose at a slightly lower temperature than the extracted cellulose. Studies on wood cellulose has shown that regenerated cellulose from $\mathrm{DMAc} / \mathrm{LiCl}$ has a slightly lower thermal stability than cellulose before dissolution (Mahadeva et al. 2013) and our data suggest that cellulose from Ulva lactuca shows the same behavior. This is probably caused by the fact that regenerated cellulose has fewer hydrogen bonds between the cellulose chains and also a lower crystallinity than cellulose before dissolution. The acid-treated cellulose had a slightly higher thermal stability than the extracted cellulose, probably because the acid-treated cellulose has higher crystallinity than the extracted cellulose. The DTG curves for the cellulose fractions show one peak corresponding to the degradation of cellulose. The peak values are as follows: T(extracted

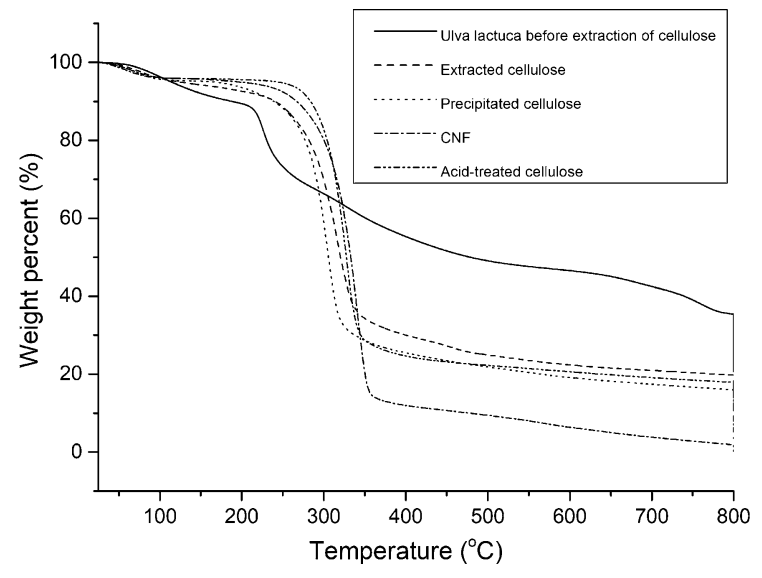

Fig. 3 TGA curves for Ulva lactuca and cellulose fractions extracted from Ulva lactuca showing the weight percent versus temperature

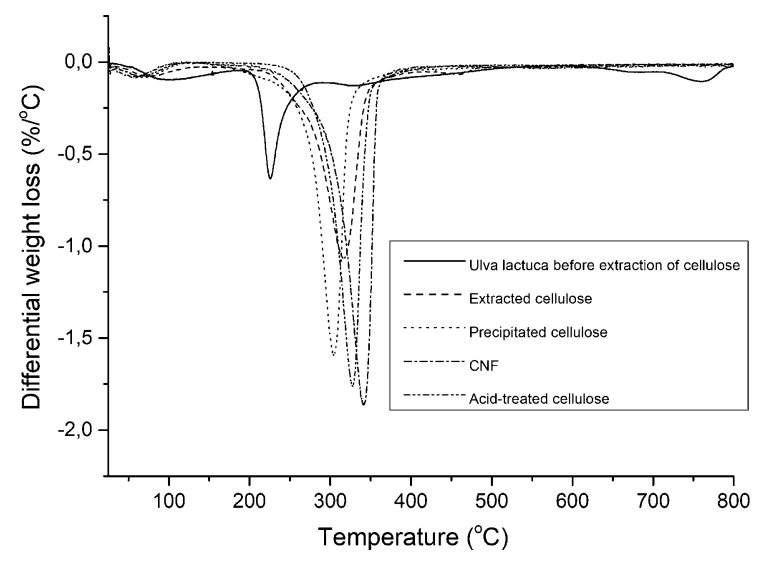

Fig. 4 DTG curves for Ulva lactuca and cellulose fractions extracted from Ulva lactuca showing the weight loss versus temperature

cellulose $)=318^{\circ} \mathrm{C}, \quad \mathrm{T}($ regenerated cellulose $)=305{ }^{\circ} \mathrm{C}, \mathrm{T}(\mathrm{CNF})=342{ }^{\circ} \mathrm{C}$, and $\mathrm{T}($ acid treated cellulose $)=328^{\circ} \mathrm{C}$.
Table 2 The char and ash contents of Ulva lactuca and the extracted cellulose fractions

\begin{tabular}{lcc}
\hline & Char \% (w/w) & Ash \% (w/w) \\
\hline Ulva lactuca before extraction of cellulose & 37.0 & 21.5 \\
Extracted cellulose & 19.7 & 5.7 \\
Regenerated cellulose & 16.0 & 3.4 \\
CNF & 1.9 & 0.0 \\
Acid-treated cellulose & 17.8 & 12.3 \\
\hline
\end{tabular}


The overall ash contents in the extracted and regenerated cellulose samples (Table 2) were significantly lower than the ash content of Ulva lactuca before extraction, probably because typical waterinsoluble inorganic substances such as metal oxides, carbonates, and/or sulfates were converted to watersoluble metal chlorides during the $\mathrm{HCl}$ treatment (the final step in the cellulose extraction). By making these impurities water-soluble they can be removed from the cellulose since the liquid phase containing the impurities is discarded after the extraction. After the homogenization process, the ash content of the extracted cellulose decreased from $5.7 \%(\mathrm{w} / \mathrm{w})$ to $0 \%(\mathrm{w} / \mathrm{w})$ which means that all inorganic impurities were removed from the cellulose during the homogenization process. The regenerated cellulose fraction shows a lower ash content than the extracted cellulose before dissolution, probably because the regenerated sample was subjected to additional washing steps after the precipitation, which likely removed additional impurities.

Morphological characterization of the extracted cellulose and $\mathrm{CNF}$

CNF produced from the extracted cellulose was assessed with FE-SEM and AFM to verify that the homogenization process was successful in converting the cellulose into individual fibrils. The SEM images (Fig. 5) show individual fibrils with a thickness and length in the nanometer range, and regions with a sheet-like structure. The sheet-like structure can possibly be non-defibrillated regions indicating the homogenization process was not able to defibrillate the cellulose completely. It is also possible that the sheet-like structures represent aggregated cellulose fibrils caused by the freeze-drying process that was performed prior to the FE-SEM analysis. The sheetlike regions can also be because the cellulose contains a xylose-glucose polysaccharide such as xyloglucan, as discussed previously and indicated by the HPAECPAD analysis. Formation of these nanofibrils requires close packing of the molecules. Linear polysaccharides like cellulose are able to form nanofibrils due to their ability to pack densely while branched polysaccharides like xyloglucan typically do not form nanofibrils. The mixture of nanofibrils and sheet-like regions is another indication that the $\mathrm{CNF}$ is a mixture of cellulose and xyloglucan where the nanofibers consist of cellulose and the sheet-like structures are xyloglucan.

The crystal structure and the crystallinity index of the cellulose fractions were estimated by XRD (Fig. 6). The extracted cellulose, acid-treated cellulose, and CNF gave rise to three peaks at $2 \theta=16^{\circ}$, $22^{\circ}$, and $34^{\circ}$, corresponding to the crystal planes ( 11 0), ( $\left.\begin{array}{lll}2 & 0 & 0\end{array}\right)$ and $\left(\begin{array}{lll}0 & 0 & 4\end{array}\right)$, respectively, sustaining the presence of crystalline regions (Sarko and Muggli 1974; Park et al. 2010; Wada and Okano 2001; French and Cintrón 2013; French 2014). These are typical peaks for the cellulose I allomorph. The XRD diffractogram of regenerated cellulose (Fig. 6e), looks different and has a broad peak at $2 \theta=21^{\circ}$ which is characteristic for the cellulose II allomorph (Chanzy et al. 1986; Stipanovic and Sarko 1976; Kolpak and Blackwell 1976). The main difference between cellulose I and II still remains a question of intense debate. One theory suggests that the main difference between the two allomorphs is the orientation of the individual cellulose chains: in cellulose I, the cellulose chains are parallel, while in cellulose II, the chains are antiparallel (Chanzy et al. 1986; Stipanovic and Sarko 1976; Kolpak and Blackwell 1976). Also, the hydrogen bond pattern between the cellulose chains is different for cellulose I and II. The conversion from cellulose I to cellulose II is an irreversible process. The crystallinity index $(\mathrm{Crl} \%)$ was calculated from the XRD diffractograms using Eq. 1 (Segal et al. 1959). The crystallinity index for the regenerated cellulose fraction could not be calculated since the value of $\mathrm{I}_{\mathrm{am}}$ could not be derived due to the broad peak at $21^{\circ}$. However, the broad peak suggests that this sample is essentially amorphous. This is a possible explanation to why the regenerated cellulose showed lower thermal stability than the extracted cellulose in the TGA analysis.

The extracted cellulose and CNF had a crystallinity index of $48 \%$ indicating that the homogenization process did not change the crystallinity to any significant extent (Table 3). However, the crystallinity index increased to $63 \%$ after the acidic treatment, probably because the acidic treatment partially removed the amorphous regions of the cellulose. The low crystallinity of the extracted cellulose and the CNF can be explained by the samples being a mixture of cellulose and xyloglucan. The xyloglucan residue might possibly interrupt the formation of cellulose crystals leading to a low crystallinity. The HPAECPAD analysis showed that xylose content decreased as 

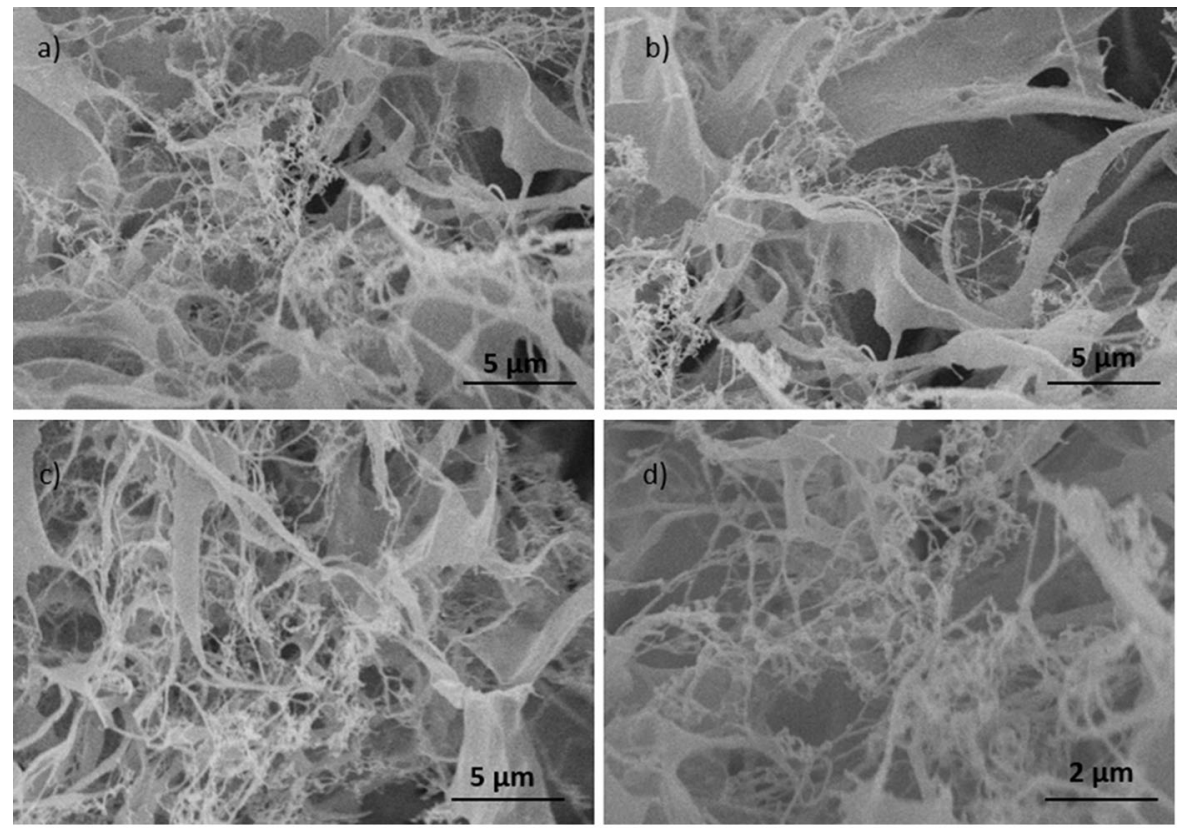

e)

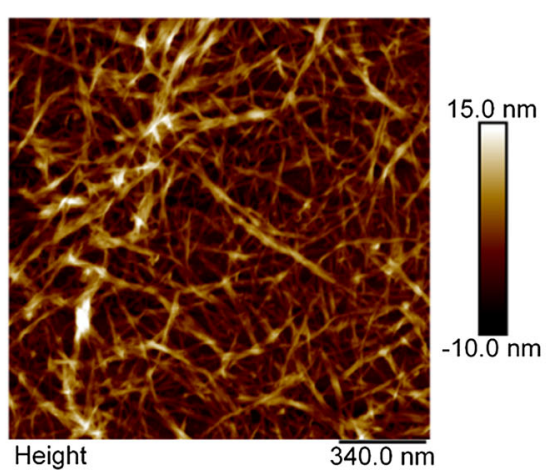

Fig. 5 a-c SEM images with $\times 10,000$ magnification of CNF produced from cellulose extracted from Ulva lactuca. d SEM image with $\times 20,000$ magnification of CNF and e AFM image of the CNF

an effect of acid-treatment, which indicates a partial removal of the xylose-glucose polysaccharide mixed with cellulose in the fractions. This would explain why the acid-treated cellulose had a higher crystallinity index than the other samples. Overall, the degree of crystallinity of the Ulva lactuca cellulose seems low. The estimated values of the crystallinity however show the crystallinity of a mixture between cellulose and xyloglucan rather than the crystallinity of the pure cellulose. Hence, even if the estimated values of the crystallinity is low it does not necessarily mean that the crystallinity of pure cellulose from Ulva lactuca is low. Studies of various algae have shown that the crystallinity of cell wall cellulose varies substantially between different classes and orders of algae
(Mihranyan 2011). In some algae, cellulose is the major component of the cell wall and the cellulose tends to be highly crystalline while other algae are characterized by lower contents and crystallinity of cell wall cellulose. In addition, the crystal structure varies between algal species (Koyama et al. 1997). Acid treatment of cellulose recovered from Cladophora green algae produced a cellulose with very high degree of crystallinity (Wada and Okano 2001), while the acid-treated cellulose fraction produced in this study did not reach a crystallinity index higher than $63 \%$. In general, the degree of crystallinity of CNF is dependent of the biomass source and on the preparation method. Gopakumar et al. (2016) report that 'crystallinity ranging from 40 to $80 \%$ has been 


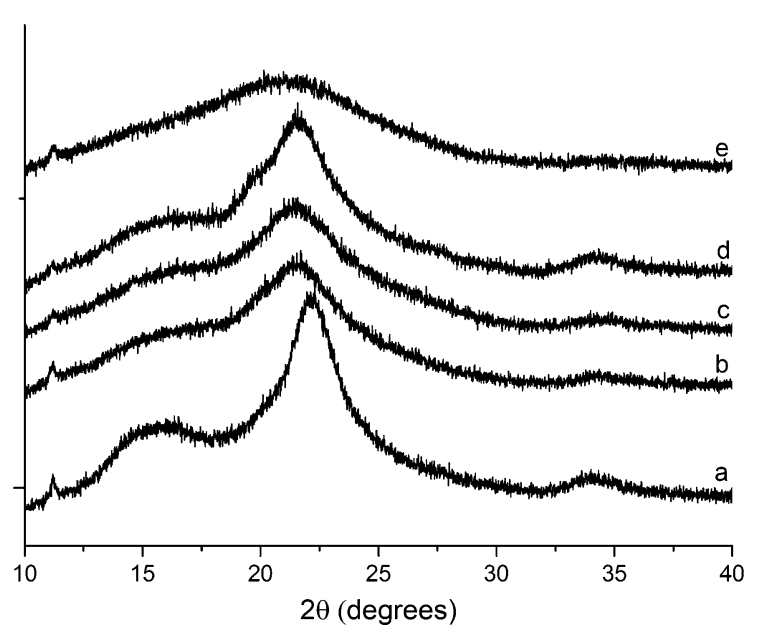

Fig. 6 XRD diffractograms of (a) reference cellulose from Spruce wood, (b) extracted cellulose (c) CNF (d) acid-treated cellulose and (e) regenerated cellulose

reported for the CNFs obtained from softwoods and hardwoods.'

In-depth carbohydrate compositional

characterization of the extracted cellulose and $\mathrm{CNF}$

Further structural investigations of the cellulose extracted from Ulva lactuca and the produced CNF were performed with solid-state NMR (Fig. 7). The reference cellulose sample shows all the characteristic signals for cellulose. Signals at 65 and $63 \mathrm{ppm}$ correspond to the C6 carbon in crystalline and amorphous regions in cellulose, respectively. The strong signals at 76 and 73 ppm correspond to the $\mathrm{C} 2$, C3, and C5 carbons. The weaker signals at 89 and $85 \mathrm{ppm}$ correspond to the $\mathrm{C} 4$ carbon in crystalline and amorphous regions in cellulose, respectively. The signal at $105 \mathrm{ppm}$ is attributed to the $\mathrm{C} 1$ carbon (Wada et al. 2004). The spectra for the cellulose samples from Ulva lactuca look similar, but some important differences can be observed. For the extracted cellulose, acid-treated cellulose and CNF, the intensity of the

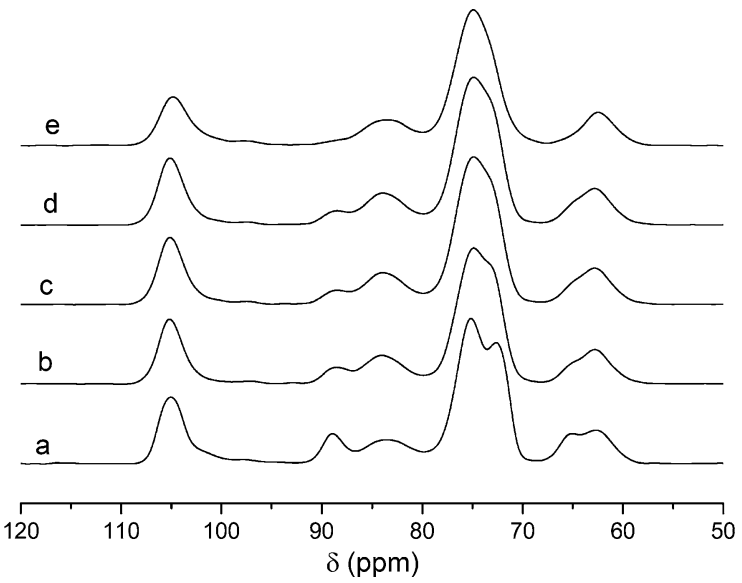

Fig. 7 The CP-MAS 13C-NMR of cellulose fractions. (a) reference cellulose from Spruce wood, (b) extracted cellulose, (c) CNF, (d) acid-treated cellulose and (e) regenerated cellulose

signal at 89 ppm corresponding to crystalline domains is lower than for the reference samples indicating that the crystallinity of these samples is lower than the crystallinity for the reference samples, which is in agreement with the XRD data (Table 3). The regenerated cellulose shows only a very faint signal at 89 ppm indicating that this sample is largely amorphous. The same behavior can be observed for the signals from the C6 carbon. In the reference sample, the signals corresponding to the crystalline regions have the same intensity as the signal from the amorphous regions. However, for the extracted, acid-treated and CNF, the amorphous signal has a higher intensity than the crystalline signal. For the regenerated cellulose, we only see the amorphous signals at $63 \mathrm{ppm}$ and $85 \mathrm{ppm}$, which is another indication that this sample is amorphous. As previously discussed, if the cellulose samples are indeed mixtures of cellulose and xyloglucan, we would expect individual signals from each monosaccharide (glucose and xylose). However, the chemical shifts for the $\mathrm{C} 1-\mathrm{C} 5$ carbons in xylose are very close to the chemical shifts for C1-C6 in glucose (Lahaye et al.
Table 3 The crystallinity index, $\operatorname{Crl}(\%)$ for cellulose fractions and $\mathrm{CNF}$ extracted from Ulva lactuca

\begin{tabular}{llll}
\hline Sample & $\mathrm{I}_{200}$ & $\mathrm{I}_{\mathrm{am}}$ & $\operatorname{Crl}(\%)=\left(\mathrm{I}_{200}-\mathrm{I}_{\mathrm{am}}\right) / \mathrm{I}_{200}$ \\
\hline Reference cellulose & 1750 & 500 & 71 \\
Extracted cellulose & 1050 & 550 & 48 \\
CNF & 1050 & 550 & 48 \\
Acid-treated cellulose & 1350 & 500 & 63 \\
\hline
\end{tabular}


1994) and since the peaks in the NMR spectra are very broad, the peaks for glucose and xylose are likely to overlap. The results from the solid-state NMR in summary sustain that the extracted cellulose fractions are mixtures of cellulose with a xylose-glucose polysaccharide. Still, just as in the case of HPAEC$\mathrm{PAD}$, the results cannot convincingly verify that the fractions contain cellulose I or II.

Optotracing was developed as a non-disruptive method to optically detect and visualize cellulose in biological tissues in their native states. The method utilizes optotracers, a class of molecular probes called oligothiophenes, which bind selectively to glucans producing a unique spectral pattern that identifies the bound target. Applying heptameric (Choong et al. 2018) and pentameric (Choong et al. 2019) optotracers, cellulose can be clearly distinguished from a range of glucans and glucose-containing heteropolysaccharides based on differences in size and stereochemistry. Here, we applied optotracing as a complementary tool to overcome the limitation of HPAEC-PAD and solidstate NMR to verify the polymeric origin of the detected xylose and glucose building blocks in the extracted cellulose. To determine if optotracing could differentiate cellulose from xyloglucan, a panel of 4 optotracers ranging from heptameric to tetrameric was screened against pure referenced samples of microcrystalline cellulose (M. cellulose), xyloglucan and xylose. For easy comparison of spectral patterns and wavelengths representing the peak amplitudes, the fluorescence emitted by optotracers in each interaction was normalized by calculating the percentage of the emitted fluorescence at each excitation wavelength relative to the highest and lowest values in the spectrum (N. RFU). The N. RFU was then plotted in Normalized Spec-Plots (Fig. 8). The wavelengths of maximum excitation (Ex. $\lambda \max )$ and emission (Em. $\lambda \max )$ are summarized in Table 4.

Analysis of the normalized Spec-Plots of h-FTAA showed visibly different spectral patterns when in interaction with cellulose and xyloglucan, which was reflected in the $5 \mathrm{~nm}$ and $11 \mathrm{~nm}$ differences in Ex. $\lambda \max$ and Em. $\lambda$ max respectively. This indicated that optotracing with h-FTAA could differentiate between cellulose and xyloglucan.

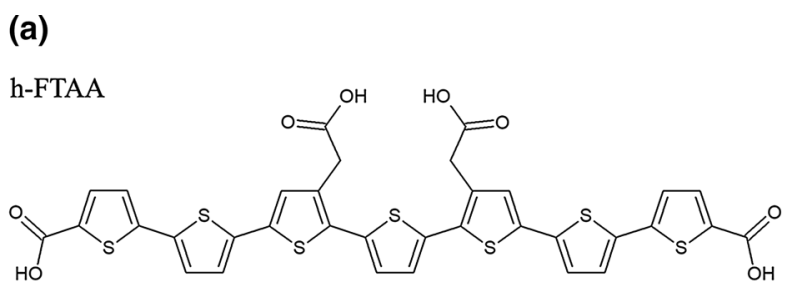

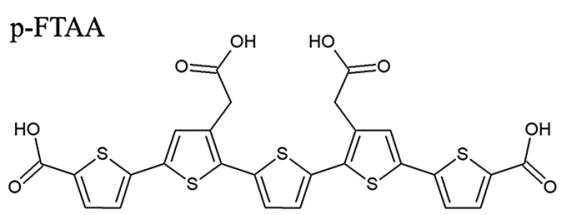

(b)

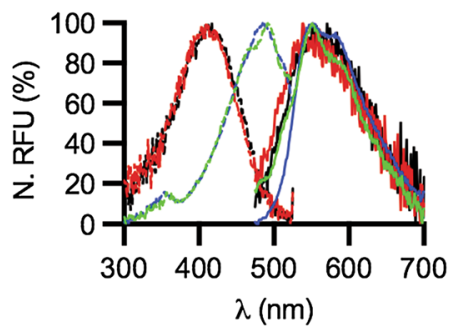

(c)

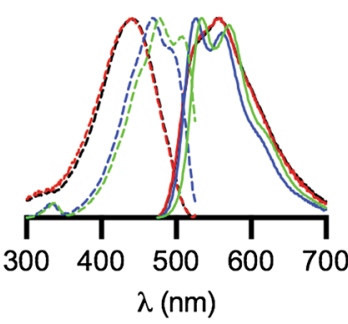

Fig. 8 a Optotracer structures, b-e spectra patterns of optotracers fluorescence emitted when $\mathrm{M}$. cellulose (green), xyloglucan (blue) and xylose (red) are interacting with b h-

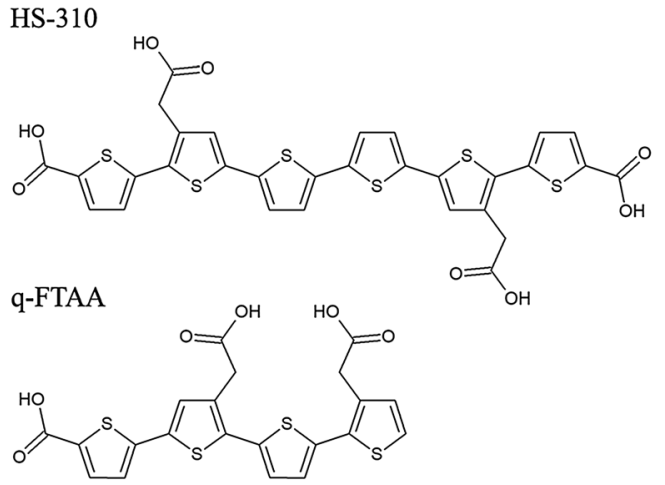

(d)

(e)
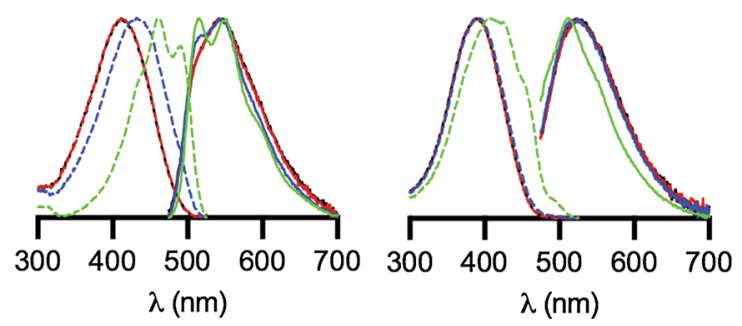

FTAA, c HS-310, d p-FTAA and e q-FTAA. Optotracer alone (black) is analyzed in parallel as a negative control 
Table 4 Summary of Ex. and Em. $\lambda$ max of h-FTAA, HS-310, p-FTAA and q-FTAA when interacting with M. cellulose, xyloglucan and xylose

\begin{tabular}{|c|c|c|c|c|c|c|c|c|}
\hline & \multicolumn{2}{|l|}{ HFTAA } & \multicolumn{2}{|l|}{ HS-310 } & \multicolumn{2}{|l|}{ PFTAA } & \multicolumn{2}{|l|}{ QFTAA } \\
\hline & Ex. $\lambda \max$ & Em. $\lambda \max$ & Ex. $\lambda \max$ & Em. $\lambda \max$ & Ex. $\lambda \max$ & Em. $\lambda \max$ & Ex. $\lambda \max$ & Em. $\lambda \max$ \\
\hline \multirow[t]{2}{*}{ M. Cellulose + optotracer } & 491 & 567 & 479 & 535 & 462 & 518 & 414 & 513 \\
\hline & & & & 571 & & 547 & & \\
\hline Xyloglucan + optotracer & 486 & 556 & 470 & 526 & 431 & 545 & 392 & 521 \\
\hline Xylose + optotracer & 406 & 559 & 440 & 555 & 413 & 545 & 390 & 525 \\
\hline Optotracer only & 417 & 566 & 441 & 556 & 413 & 545 & 389 & 526 \\
\hline
\end{tabular}

Identical preparations of optotracer alone was used as a control

Comparison of the normalized Spec-Plots of xylose and xyloglucan indicated that the spectral pattern collected of xyloglucan was not due to interactions with monosaccharide, but more likely due to interactions with the xyloglucan polysaccharide. To determine if the detection of xyloglucan, like cellulose, was due to binding of the $\beta$-1,4-glucan segments, $1 \mathrm{mg} / \mathrm{mL}$ of each polysaccharide were screened against hexameric (HS-310), pentameric (p-FTAA) and tetrameric (q-FTAA) optotracers. Analysis of each normalized spec. plot showed unique spectral patterns in all instances, whereby the spectral pattern of cellulose and xyloglucan were different and distinct. This indicates that the interaction between optotracers and xyloglucan was along segments of the polysaccharide substituted with 1,6-linked xylose side chains.

Observing the enhanced resolution of optotracing by the comparative analysis of multiple optracers, we applied the panel of heptameric to tetrameric optotracers to CNF produced from Ulva lactuca. M. cellulose was screened alongside as a cellulose reference of high purity (Fig. 9, Table 5). Comparison of the normalized spec plot of CNF and M. cellulose revealed highly similar spectral patterns, Ex. $\lambda \max$ and Em. $\lambda$ max of bound optotracers. p-FTAA was the only exception, wherein $M$. cellulose binding
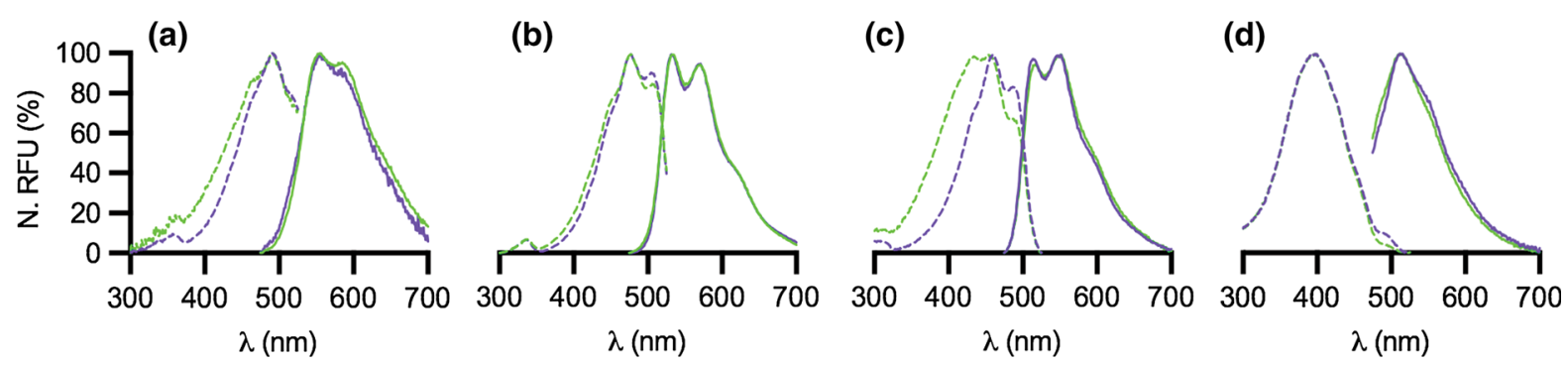

Fig. 9 Spectra patterns of optotracers fluorescence emitted when M. cellulose (green) and CNF (purple) a h-FTAA, b HS-310, c pFTAA and d q-FTAA

Table 5 Summary of Ex. and Em. $\lambda$ max of h-FTAA, HS-310, p-FTAA and q-FTAA when interacting with M. cellulose and CNF

\begin{tabular}{|c|c|c|c|c|c|c|c|c|}
\hline & \multicolumn{2}{|l|}{ HFTAA } & \multicolumn{2}{|l|}{ HS-310 } & \multicolumn{2}{|l|}{ PFTAA } & \multicolumn{2}{|l|}{ QFTAA } \\
\hline & Ex. $\lambda \max$ & Em. $\lambda \max$ & Ex. $\lambda \max$ & Em. $\lambda \max$ & Ex. $\lambda \max$ & Em. $\lambda \max$ & Ex. $\lambda \max$ & Em. $\lambda \max$ \\
\hline \multirow[t]{2}{*}{ M. Cellulose + optotracer } & 492 & 556 & 477 & 538 & 446 & 537 & 399 & 514 \\
\hline & & & & 570 & & 546 & & \\
\hline $\mathrm{CNF}+$ optotracer & 493 & 553 & 476 & 533 & 461 & 548 & 396 & 513 \\
\hline
\end{tabular}


produced an additional Ex. $\lambda \max$ at $446 \mathrm{~nm}$, which may be a reflection of the highly dense crystal morphology of M. cellulose. Analysis by the optotracer panel indicates that glucose detected in CNF (Table 1) originates from cellulose. The absence of other spectral patterns reminiscent of xyloglucan as described in Fig. 8, suggests that the xylose fraction detected during monosaccharide analysis is likely due to the presence of another glucose-xylose copolymer. This copolymer could possibly be the linear $\beta-(1,4)$ xyloglucan reported in previous studies (Lahaye et al. 1994; Lahaye and Robic 2007) which would then differ from the branched $\beta-(1,6)$ xyloglucan used as the reference.

\section{Conclusions}

Cellulose was successfully extracted by sequential treatment from the green macroalgae Ulva lactuca collected along the Swedish west coast. The recovered cellulose was then disintegrated into lignin-free cellulose nanofibrils (CNF) using a mechanical homogenization process without any enzymatic or chemical pre-treatment prior to the homogenization process. In parallel, regenerated cellulose and acid-treated cellulose were produced. The yield of extracted cellulose was overall low because young Ulva lactuca individuals were used.

Monosaccharide analysis of the extracted cellulose and CNF shows that it contains mainly glucose, but also a fraction of xylose indicating that the produced cellulose fractions contain a mixture of cellulose and a xylose-glucose polysaccharide, such as xyloglucan. Acid-treatment or dissolution and regeneration of the cellulose partly removed the xyloglucan residues. Solid-state NMR and FTIR analyses support the hypothesis of samples being mixtures of cellulose and xyloglucan but cannot fully verify the existence of cellulose I or II. Optotracing shows that CNF extracted from Ulva lactuca exhibited the same spectral patterns as that of $M$. cellulose originating from cotton. Absence of similarity of this spectral pattern with that of a pure xyloglucan reference indicates cellulose of high purity present. Here, the ability to analyze carbohydrates in its polymeric state was key to uncovering the origin of xylose in extracted cellulose samples.
Characterization of the morphology of the CNF by FE-SEM and AFM shows both nanofibrils similar to those found in lignocellulose and regions with a sheetlike structure. Thermal analysis of the CNF shows that it is free of inorganic ash and thermally stable up to $260{ }^{\circ} \mathrm{C}$. XRD analysis showed characteristic peaks for the cellulose I allomorph and the crystallinity index was estimated to $48 \%$. After dissolution in DMAc/ $\mathrm{LiCl}$ and precipitation in water, the crystal structure of the cellulose changed from cellulose I to cellulose II and the sample became largely amorphous.

Acknowledgments Open access funding provided by Royal Institute of Technology. The authors thank Swedish Foundation for Strategic Research (SSF), Project Number RBP14-0045 for financial support. Thanks to Carl Moser at the division of Wood Chemistry and Pulp Technology, KTH Royal Institute of Technology, for running the homogenizer. Funding was provided by Erling-Persson Family Foundation and Getinge $\mathrm{AB}$.

\section{Compliance with ethical standards}

Conflict of interest The authors declares that they no conflict of interest.

Open Access This article is licensed under a Creative Commons Attribution 4.0 International License, which permits use, sharing, adaptation, distribution and reproduction in any medium or format, as long as you give appropriate credit to the original author(s) and the source, provide a link to the Creative Commons licence, and indicate if changes were made. The images or other third party material in this article are included in the article's Creative Commons licence, unless indicated otherwise in a credit line to the material. If material is not included in the article's Creative Commons licence and your intended use is not permitted by statutory regulation or exceeds the permitted use, you will need to obtain permission directly from the copyright holder. To view a copy of this licence, visit http://creativecommons.org/licenses/by/4.0/.

\section{References}

Åslund A, Sigurdson CJ, Klingstedt T, Grathwohl S, Bolmont T, Dickstein DL, Glimsdal E, Prokop S, Lindgren M, Konradsson P, Holtzman DM, Hof PR, Heppner FL, Gandy S, Jucker M, Aguzzi A, Hammarström P, Nilsson KPR (2009) Novel pentameric thiophene derivatives for in vitro and in vivo optical imaging of a plethora of protein aggregates in cerebral amyloidoses. ACS Chem Biol 4:673-684. https://doi.org/10.1021/cb900112v

Bettaieb F, Khiari R, Dufresne A, Mhenni MF, Belgacem MN (2015) Mechanical and thermal properties of Posidonia oceanica cellulose nanocrystal reinforced polymer. 
Carbohydr. Polym. 123:99-104. https://doi.org/10.1016/j. carbpol.2015.01.026

Bobin-Dubigeon C, Lahaye M, Guillon F, Barry J, Gallant DJ (1997) Factors limiting the biodegradation of Ulva sp cellwall polysaccharides. J Sci Food Agric 75(3):341-351. https://doi.org/10.1002/(SICI)1097-0010(199711)75:3\% 3c341:AID-JSFA888\%3e3.0.CO;2-B

Chanzy H, Henrissat B, Vuong R, Revol J-F (1986) Structural changes of cellulose crystals during the reversible transformation cellulose $\mathrm{I} \rightarrow \mathrm{III}_{\mathrm{I}}$ in Valonia. Holzforschung 40(Suppl):25-30

Chen YW, Lee HV, Juan JC, Phang SM (2016) Production of new cellulose nanomaterial from red algae marine biomass Gelidium elegans. Carbohydr Polym 151:1210-1219. https://doi.org/10.1016/j.carbpol.2016.06.083

Choong FX, Bäck M, Steiner SE, Melican K, Nilsson KPR, Edlund U, Richter-Dahlfors A (2016) Nondestructive, realtime determination and visualization of cellulose, hemicellulose and lignin by luminescent oligothiophenes. Sci Rep 6:35578. https://doi.org/10.1038/srep35578

Choong FX, Bäck M, Schultz A, Nilsson KPR, Edlund U, Richter-Dahlfors A (2018) Stereochemical identification of glucans by oligothiophenes enables cellulose anatomical mapping in plant tissues. Sci Rep 8:3108. https://doi.org/ 10.1038/s41598-018-21466-y

Choong FX, Lantz L, Shirani H, Schultz A, Nilsson KPR, Edlund U, Richter-Dahlfors A (2019) Stereochemical identification of glucans by a donor-acceptor-donor conjugated pentamer enables multi-carbohydrate anatomical mapping in plant tissues. Cellulose 26:4253-4264. https:// doi.org/10.1007/s10570-019-02381-5

Cronshaw J, Myers A, Preston RD (1958) A chemical and physical investigation of the cell walls of some marine algae. Biochim Biophys Acta 27:89-103. https://doi.org/ 10.1016/0006-3002(58)90295-6

Dennis DT, Preston RD (1961) Constitution of cellulose microfibrils. Nature 191:667-668. https://doi.org/10.1038/ $191667 \mathrm{a} 0$

French AD (2014) Idealized powder diffraction patterns for cellulose polymorphs. Cellulose 21:885-896

French AD, Cintrón MS (2013) Cellulose polymorphy, crystallite size, and the Segal crystallinity index. Cellulose 20:583-588

Gopakumar DA, Thomas S, Grohens Y (2016) Chapter 8: Nanocelluloses as innovative polymers for membrane applications. In: Puglia D, Fortunati E, Kenny JM (eds) Multifunctional polymeric nanocomposites based on cellulosic reinforcements. Elsevier, Amsterdam, pp 253-275. https://doi.org/10.1016/C2014-0-04565-0

Griggs D, Stafford-Smith M, Gaffney O, Rockström J, Öhman MC, Shyamsundar P, Noble I (2013) Sustainable development goals for people and planet. Nature 495(7441):305. https://doi.org/10.1038/495305a

Halib N, Perrone F, Cemazar M, Dapas B, Farra R, Abrami M, Murena L (2017) Potential applications of nanocellulosecontaining materials in the biomedical field. Materials 10(8):977. https://doi.org/10.3390/ma10080977

Hughey JR, Maggs CA, Mineur F, Jarvis C, Miller KA, Shabaka SH, Gabrielson PW (2019) Genetic analysis of the Linnaean Ulva lactuca (Ulvales, Chlorophyta) holotype and related type specimens reveals name misapplications, unexpected origins, and new synonymies. J Phycol. https:// doi.org/10.1111/jpy.12860 (in press)

Kargarzadeh H, Mariano M, Gopakumar D, Ahmad I, Thomas S, Dufresne A, Huang J, Lin N (2018) Advances in cellulose nanomaterials. Cellulose 25:2151-2189. https://doi. org/10.1007/s10570-018-1723-5

Klingstedt T, Åslund A, Simon RA, Johansson LBG, Mason JJ, Nyström S, Hammarström P, Nilsson KPR (2011) Synthesis of a library of oligothiophenes and their utilization as fluorescent ligands for spectral assignment of protein aggregates. Org Biomol Chem 9:8356-8370. https://doi. org/10.1039/c1ob05637a

Kolpak FJ, Blackwell J (1976) Determination of the structure of cellulose II. Macromolecules 9:273-278. https://doi.org/ 10.1021/ma60050a019

Koyama M, Sugiyama J, Itoh T (1997) Systematic survey on crystalline features of algal celluloses. Cellulose 4:147-160. https://doi.org/10.1023/A:1018427604670

Lahaye M, Robic A (2007) Structure and functional properties of ulvan, a polysaccharide from green seaweeds. Biomacromol 8(6):1765-1774. https://doi.org/10.1021/ bm061185q

Lahaye M, Jegou D, Buleon A (1994) Chemical characteristics of insoluble glucans from the cell wall of the marine green alga Ulva lactuca (L.) Thuret. Carbohydr Res 262:115-125. 6215(94)84008-3

Lakshmi DS, Trivedi N, Reddy CRK (2017) Synthesis and characterization of seaweed cellulose derived carboxymethyl cellulose. Carbohydr Polym 157:1604-1610. https://doi.org/10.1016/j.carbpol.2016.11.042

Lavoine N, Desloges I, Dufresne A, Bras J (2012) Microfibrillated cellulose-its barrier properties and applications in cellulosic materials: a review. Carbohydr Polym 90(2):735-764. https://doi.org/10.1016/j.carbpol.2012.05. 026

Mahadeva S, Yeol Yang S, Kim J (2013) Effects of solvent systems on its structure, properties and electromechanical behavior of cellulose electro-active paper. Curr Organ Chem 17(1):83-88. https://doi.org/10.2174/ 138527213805289114

Mihranyan A (2011) Cellulose from Cladophorales green algae: from environmental problem to high-tech composite materials. J Appl Polym Sci 119:2449-2460. https://doi. org/10.1002/app.32959

Naderi A (2017) Nanofibrillated cellulose: properties reinvestigated. Cellulose 24:1933-1945. https://doi.org/10.1007/ s10570-017-1258-1

Park S, Baker JO, Himmel ME, Parilla PA, Johnson DK (2010) Cellulose crystallinity index: measurement techniques and their impact on interpreting cellulase performance. Biotechnol Biofuels 3:1-10. https://doi.org/10.1186/17546834-3-10

Potthast A, Rosenau T, Sixta H, Kosma P (2002) Degradation of cellulosic materials by heating in DMAc/LiCl. Tetrahedron Lett 43:7757-7759. https://doi.org/10.1016/S00404039(02)01767-7

Potthast A, Rosenau T, Sartori J, Sixta H, Kosma P (2003) Hydrolytic processes and condensation reactions in the cellulose solvent system N, N-dimethylacetamide/lithium chloride. Part 2: degradation of cellulose. Polymer 
44(1):7-17. 3861(02)00751-6

https://doi.org/10.1016/S0032-

Prybysz P, Buzała K material base of the paper industry with regard to the sustainable development concept. Fibres Text East Eur 22(4):18-23

Ray B, Lahaye M (1995) Cell-wall polysaccharides from the marine green alga Ulva "rigida"(Ulvales, Chlorophyta). Extraction and chemical composition. Carbohydr Res 274:251-261. https://doi.org/10.1016/00086215(95)00138-J

Rocha I, Lindh J, Hong J, Strømme M, Mihranyan A, Ferraz N (2018) Blood compatibility of sulfonated cladophora nanocellulose beads. Molecules 23(3):601. https://doi.org/ 10.3390/molecules23030601

Sarko A, Muggli R (1974) Packing analysis of carbohydrates and polysaccharides. III. Valonia cellulose and cellulose II. Macromolecules 7:486-494. https://doi.org/10.1021/ ma60040a016

Schiener P, Black KD, Stanley MS, Green DH (2015) The seasonal variation in the chemical composition of the kelp species Laminaria digitata, Laminaria hyperborea, Saccharina latissima and Alaria esculenta. Appl Phycol 27(1):363-373. https://doi.org/10.1007/s10811-014-03271

Segal L, Creely JJ, Martin AE Jr, Conrad CM (1959) An Empirical method for estimating the degree of crystallinity of native cellulose using the X-ray diffractometer. Text Res J 29(10):786-794. https://doi.org/10.1177/ 004051755902901003

Shanmugam K, Varanasi S, Garnier G, Batchelor W (2017) Rapid preparation of smooth nanocellulose films using spray coating. Cellulose 24(7):2669-2676. https://doi.org/ 10.1007/s10570-017-1328-4

Siddhanta AK, Prasad K, Meena R, Prasad G, Mehta GK, Chhatbar MU, Oza MD, Kumar S, Sanandiya ND (2009) Profiling of cellulose content in Indian seaweed species. Biores Technol 100:6669-6673. https://doi.org/10.1016/j. biortech.2009.07.047

Siddhanta AK, Chhatbar MU, Mehta GK, Sanandiya ND, Kumar S, Oza MD, Meena R (2011) The cellulose contents of Indian seaweeds. J Appl Phycol 23(5):919-923. https:// doi.org/10.1007/s10811-010-9599-2

Siddhanta AK, Kumar S, Mehta GK, Chhatbar MU, Oza MD, Sanandiya ND, Kondaveeti S (2013) Cellulose contents of some abundant Indian seaweed species. Nat Prod Commun
8(4):497-500. 1934578X1300800423

https://doi.org/10.1177/

Singh S, Gaikwad KK, Park SI, Lee YS (2017) Microwaveassisted step reduced extraction of seaweed (Gelidiella aceroso) cellulose nanocrystals. Int $\mathrm{J}$ Biol Macromol 99:506-510. https://doi.org/10.1016/j.ijbiomac.2017.03. 004

Siró I, Plackett D (2010) Microfibrillated cellulose and new nanocomposite materials: a review. Cellulose 17(3):459-494. https://doi.org/10.1007/s10570-010-9405y

Starko S, Mansfield SD, Martone PT (2018) Cell wall chemistry and tissue structure underlie shifts in material properties of a perennial kelp. Eur J Phycol 53(3):307-317. https://doi. org/10.1080/09670262.2018.1449013

Stipanovic AJ, Sarko A (1976) Packing analysis of carbohydrates and polysaccharides. 6. Molecular and crystal structure of regenerated cellulose II. Macromolecules 9:851-857. https://doi.org/10.1021/ma60053a027

Taboada C, Millan R, Miguez I (2010) Composition, nutritional aspects and effect on serum parameters of marine algae Ulva rigida. J Sci Food Agric 3:445-449. https://doi.org/ 10.1002/jsfa.3836

Tayeb A, Amini E, Ghasemi S, Tajvidi M (2018) Cellulose nanomaterials-binding properties and applications: a review. Molecules 23(10):2684. https://doi.org/10.3390/ molecules 23102684

Ververis C, Georghiou K, Christodoulakis N, Santas P, Santas R (2004) Fiber dimensions, lignin and cellulose content of various plant materials and their suitability for paper production. Ind Crops Prod 19(3):245-254. https://doi.org/10. 1016/j.indcrop.2003.10.006

Wada M, Okano T (2001) Localization of I $\alpha$ and I $\beta$ phases in algal cellulose revealed by acid treatments. Cellulose 8:183-188. https://doi.org/10.1023/A:1013196220602

Wada M, Heux L, Sugiyama J (2004) Polymorphism of cellulose I family: reinvestigation of cellulose IV. Biomacromol 5(4):1385-1391. https://doi.org/10.1021/bm0345357

Zeronian SH, Inglesby MK (1995) Bleaching of cellulose by hydrogen peroxide. Cellulose 2(4):265-272. https://doi. org/10.1007/BF00811817

Publisher's Note Springer Nature remains neutral with regard to jurisdictional claims in published maps and institutional affiliations. 